\title{
The use of musical interactions to collaborate with teaching staff and specialist services at a special education school.
}

An exegesis presented in partial fulfilment for the degree of

Master of Music Therapy

New Zealand School of Music

Wellington, New Zealand

Devin Brooks

2017 


\begin{abstract}
This research aimed to investigate how a student music therapist used musical interactions to collaborate with teaching staff and specialist services at a special education school in New Zealand. Music therapists in this context are able to collaborate by assisting and supporting other therapy professionals and staff. I was particularly interested in how the 'music' served as a collaborative tool within the school and what was meaningful that developed from these musical interactions between school members.
\end{abstract}

Through secondary analysis of my reflective clinical journal notes I was able to explore how I used musical interactions to collaborate. Data was coded, sorted into meaning units, and themes were then drawn out using thematic analysis.

The findings suggested that musical interactions promoted staff experiences of music making with others as well as supporting student goals, by corresponding to the classroom learning agenda. Musical interactions gave support in resourcing staff to become facilitators of music in the classroom, as well as supporting the little moments when life at a special education setting can be challenging. Lastly, musical interactions were perceived to build a sense of community within the school. Musicmaking and facilitation of music in mostly informal settings seemed to support connecting and relationship building between students and staff. 


\section{Table of Contents}

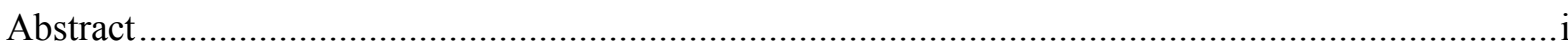

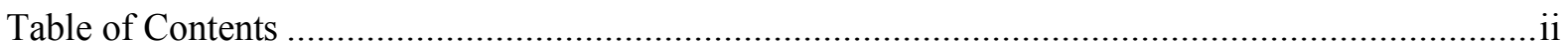

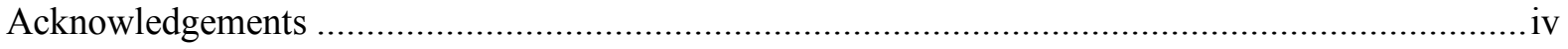

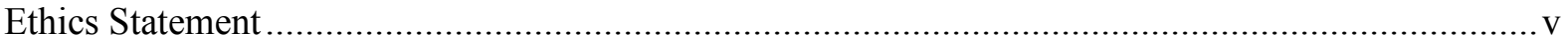

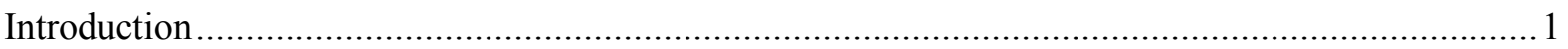

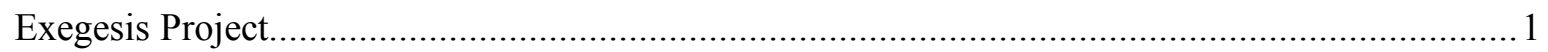

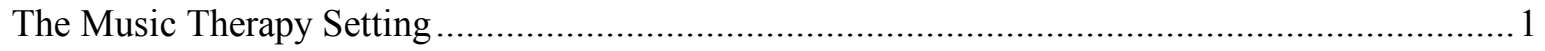

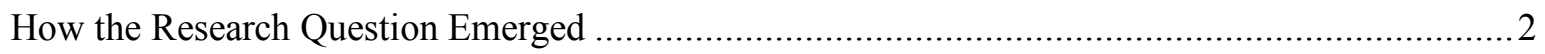

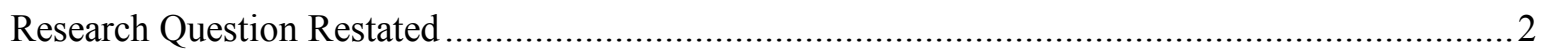

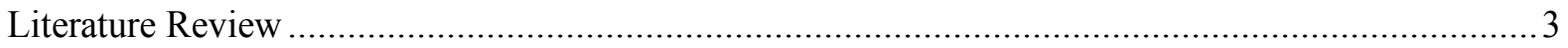

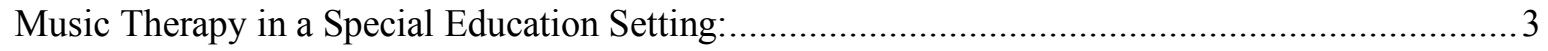

Interactive Music Therapy Techniques within Special Education: ............................................ 4

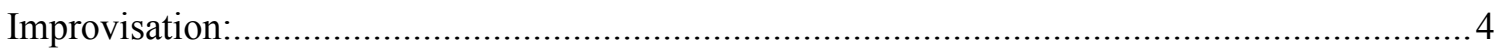

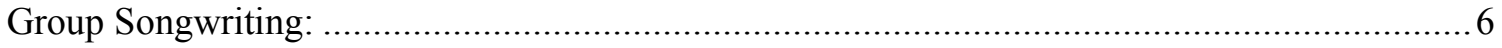

Music Therapy Supporting the Development of Play Skills within Special Education:....................

The Relationship of Music Therapy and Intensive Interaction in Special Education:...................... 8

Collaboration with Specialist Services and Teaching Staff: ........................................................

Summary:

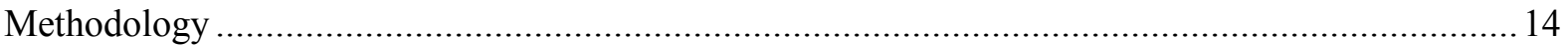

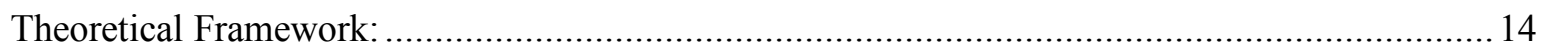

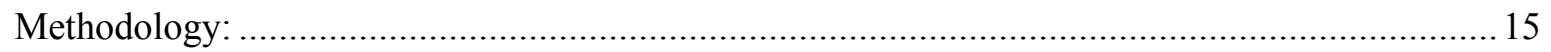

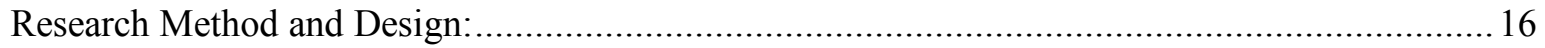

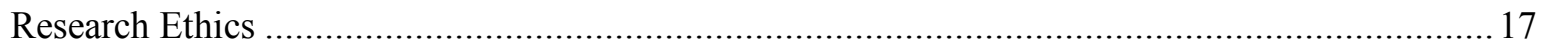

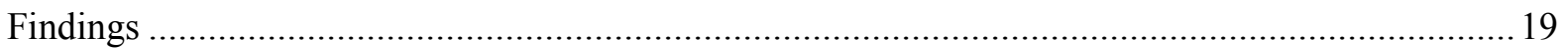

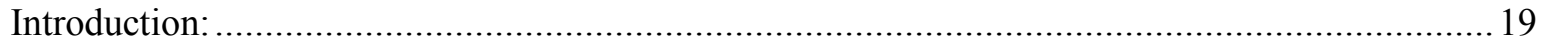

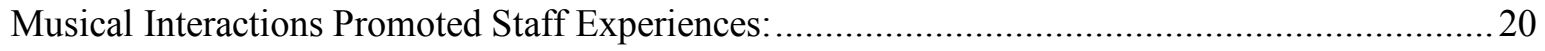


Vignette:

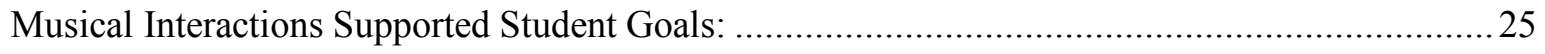

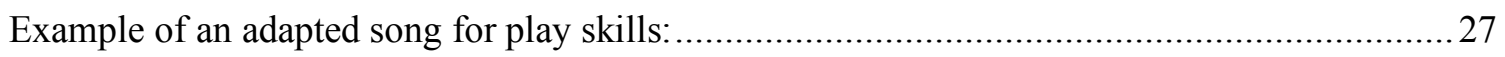

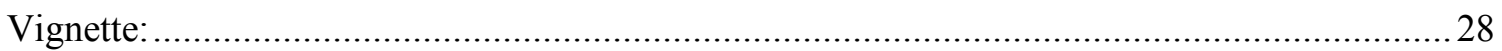

Example of the original composition used in vignette above ................................................29

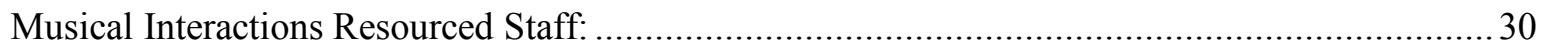

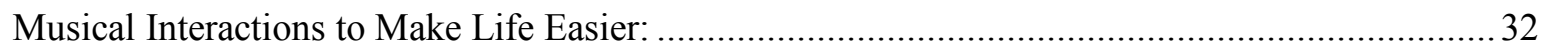

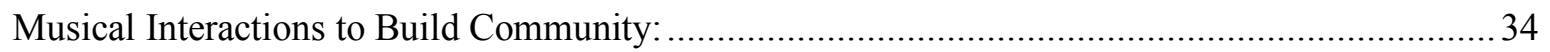

Vignette:

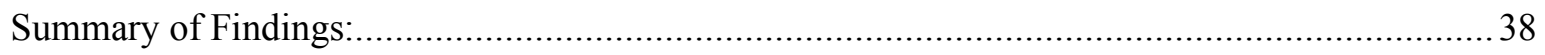

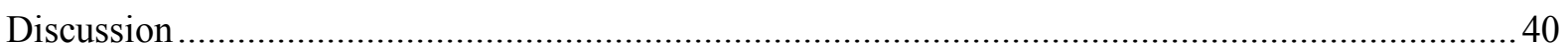

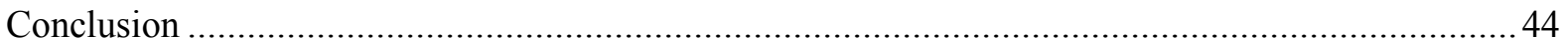

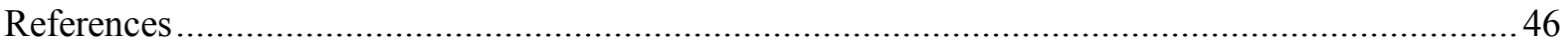

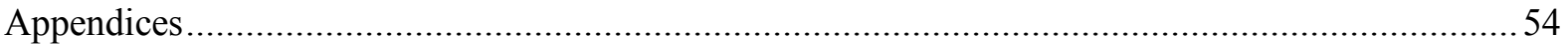

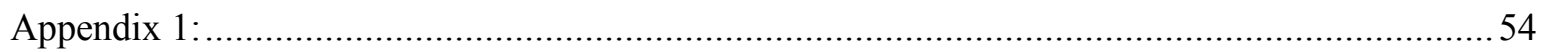

Raw Data from Reflective Clinical Journal Notes:................................................................. 54

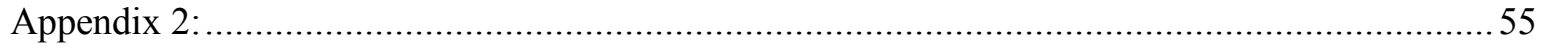

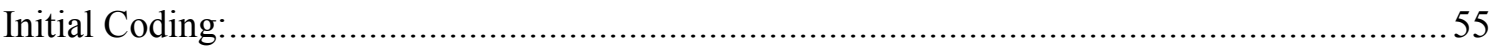

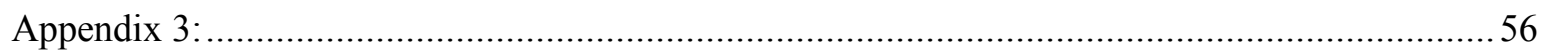

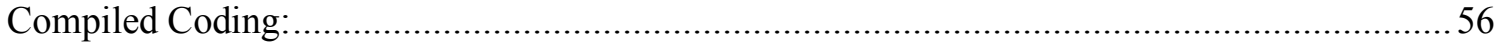

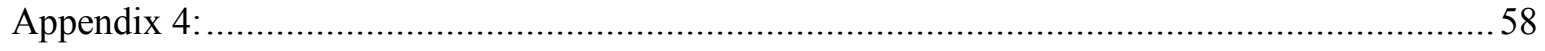

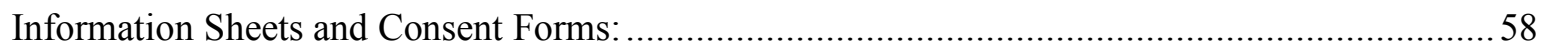

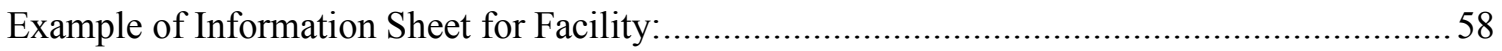

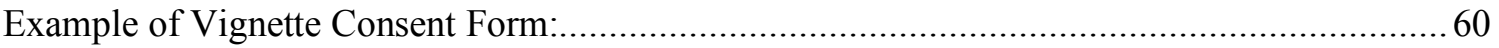




\section{Acknowledgements}

Thank you to Dr Sarah Hoskyns for her encouragement, kindness and valuable guidance throughout the research process as well as being a most wonderful professor.

Thank you to Dr Daphne Rickson for introducing me to her infectiously, inspiring work. As well as providing meaningful support as I navigated through the two years at NZSM.

Lastly, thank you to my incredible parents and dearest friends for offering generous amounts of support and love throughout this journey. 


\section{Ethics Statement}

This research project was given ethical approval by the Victoria University of Wellington's Human Ethics Committee under the NZSM Master of Music therapy Programme ethical template for student research in NZSM 526 undertaken as observational studies, theoretical or case study research or action research. Approval \# 22131. 


\section{Introduction}

\section{Exegesis Project}

As part of the requirements towards my Master of Music Therapy, I completed a placement as a student music therapist at a school in the special education network in New Zealand. I was required to complete 750 hours of clinical practice throughout the year. These hours were accumulated over weekly, two full work days which coincided with the school term and holiday scheduling. At the beginning of term three in July, I was asked to attend an additional half day which resulted in an average of 20 hours of placement work each week. The placement operated between February and December 2017

I was also required to investigate and submit an exegesis which highlighted an aspect of my work that conveyed valuable interest to myself as a student researcher and practitioner. This research study combines with other music therapy practice requirements in fulfillment of the Master of Music Therapy.

\section{The Music Therapy Setting}

This study has focussed on my work on placement at Allenvale School, an urban special education school in New Zealand ${ }^{1}$. The school is made up of a large body of qualified staff including managers, teachers, teacher's aides, speech language therapists, a physiotherapist, an occupational therapist, psychologist and a music therapist. The students who are enrolled at the school are those aged 5 to 21 years of age and have complex needs including intellectual, communication and physical disabilities. The school consists of a Specialist Services team that works jointly supporting the teachers and students. They work as part of the school team to help develop and implement appropriate programmes that will enable the students to access

\footnotetext{
${ }^{1}$ The School made a special request to be named in this research, and staff and students were alerted to this issue within the informed consent process.
} 
the curriculum and to develop living skills. The school has a strong emphasis on communication with three speech and language therapists being amongst the specialist team. The role of music therapy is to work collaboratively with the team, using music to support the needs and learning of the students, particularly in the areas of developing preverbal communication skills, supporting sensory and emotional needs, and improving social and physical skills.

\section{How the Research Question Emerged}

At the early stages of the placement I began to experience the ways in which joint work was shaping my practice as a student music therapist. I realised the need to gain understanding on how to collaborate efficiently and appropriately with the staff around me. In particular, I was interested in investigating how the role of "music" assisted in collaboration with the teaching staff and specialist services at the school as well as exploring how I facilitated those interactions in a meaningful way.

\section{Research Question Restated}

This research focuses on the question: How did a student music therapist use musical interactions to collaborate with teaching staff and specialist services in a special education school? 


\section{Literature Review}

\section{Music Therapy in a Special Education Setting²:}

There is a considerable amount of literature which focusses on the application of music therapy within special education settings. Music therapy is considered valuable to support the needs of children with intellectual and physical disabilities (Oldfield, 2006; Boxil, Chase, 2007; Thompson \& McFerran, 2015; Raglioa, Traficanteb, Oasi, 2009; Geretsegger, Elefant, Mössler, Gold, 2014). Music therapy can potentially assist development in therapeutic goals such as communication, social interaction, motor development, emotional \& psychological needs and sensory needs. Many of these publications highlight that music serves as a fundamentally enjoyable and stimulating experience for children with complex needs. The use of musical activities can motivate and engage the children in a way that is encouraging and empowering (Thompson \& McFerran, 2015). Music has the ability to facilitate communication that is non-verbal through musical conversation and self-expression (Stevenson, 2003). This type of non-verbal communicative approach has been documented as being beneficial for children experiencing Autism Spectrum Disorder (Geretsegger, Elefant, Mössler, Gold, 2014; Raglioa, Traficanteb, Oasi, 2009; Brunk, 1999; Stevenson, 2003; Thompson \& McFerran, 2015).

Working within the context of special education can be challenging for educators to support children with complex needs (Macintyre, 2016; Rickson \& McFerran, 2014; Aldridge, Kern, \& Porter, 2006). Strategies are put in place in order to find ways of accommodating these challenges so that students can access the curriculum. Macintyre (2016) book, resources teachers, support staff and parents in ways they can

\footnotetext{
${ }^{2}$ The terminology 'Special Education' has been modified to 'Learning Support' by the Ministry of Education. This is to represent a more inclusive model for children with learning support needs. However, the terminology used in this research reflects the current term represented by the school.
} 
support children with autism and complex needs to learn. Macintyre communicates ways in which music such as singing and music making can be positive in developing learning over time. Therefore, there is information supporting the valuable need for music therapist's in special education settings where they can be assisting the learning of children with complex needs.

\section{Interactive Music Therapy Techniques within Special Education:}

A technique is defined as an operation or interaction to elicit an immediate response from the client or to shape his/her immediate experience (Bruscia, 1987, p.18). Music therapy techniques are used by music therapists to build interpersonal relationships (Oldfield, 2006). Oldfield states how interactive music therapy techniques were used alongside children with Autism Spectrum Disorder and their families. She explains how the use of non-verbal musical interplay contributed to the development of social interaction. Interactive music therapy techniques of non-verbal musical interplay can be explored in both paired or (recognized as partnered or) group musical improvisation. Compared to language, music provides a less confronting and more fluid approach to communication and meaning (Carroll \& Lefebvre, 2013; McFerran, 2010; Oldfield, 2006; Wigram, 2004).

\section{Improvisation:}

Carroll \& Lefebvre (2013) describe the use music therapy techniques to help encourage and contain improvisations within therapy. They explain the use of musical techniques that contribute to the "moments of therapeutic encounter", which are “establishing contact, eliciting responses, structuring responses, redirecting responses, and working with the client on deeper intrapersonal and interpersonal levels" (Carroll \& Lefebvre, 2013, p.7). As the therapeutic process is unfolding, a music therapist may 
include a number of music therapy techniques in order to elicit therapeutic responses. However, it is important to understand how a music therapist facilitates the use of musical techniques since the way they are used can be more valuable than the technique itself (Wigram, 2004; Carroll \& Lefebvre, 2013; McFerran, 2010; Bruscia, 1987). The use of interactive music therapy techniques in order to elicit a therapeutic response during moments of therapeutic encounter in improvisations are further explained and defined by Carroll \& Lefebvre (2013) as:

- Establishing Contact: Musical techniques used to establish contact and promote the clients' awareness of self and of the presence and/or music of the therapist.

- Elicit Responses: Musical techniques are used to encourage and sustain client's responses ... Giving the client more control.

- Structure Responses: Musical techniques are used to structure and contain the client's responses.

- Guide the Client Toward Greater Freedom of Expression: Musical techniques are used to encourage musical exploration and discovery.

- Work with the Client on Deeper Intrapersonal and Interpersonal Levels: Music techniques are used to encourage the expression of conscious or repressed feelings, and to help bring greater awareness and insight. These techniques can often be used when taking a psychodynamic perspective. (Caroll \& Lefebvre, 2013, p.7)

This explanation of the use of music therapy techniques in order to guide therapeutic moments of encounter can be related to relationship building with a music therapist working with children with Autism Spectrum Disorder or other complex needs. This type of non-verbal communicative interaction is a subtle, often indirect process, whereby the music therapist can connect, build a therapeutic relationship, and assist in guiding the participant towards interest and engagement with another person (Wigram, 2004; Carroll \& Lefebvre, 2013). These authors provide detailed information about how musical improvisation techniques can shape this process. 


\section{Group Songwriting:}

Group songwriting as an interactive music therapy technique can support the building of relationships and awareness of one's identity for children and adolescents in special education settings (McFerran, 2010; Baker \& Wigram, 2005). The technique of songwriting may invoke the preconceived idea that one must have a certain cognitive ability, reserved for verbal groups whom can understand the process of writing a song (Bertolami \& Martino, 2002). However, through a modified approach to basic songwriting, opportunities can be given to lower functioning children and adolescents for them to engage in this interactive therapeutic activity (Gosine, Hawksley \& Quinn, 2017). Through songwriting, children with complex needs have the space where they may begin to be more aware of others, to notice themselves within a group context, and acknowledge one another through these individual expressions. When working alongside children or adolescents who present with less complex needs, songwriting can be a valuable technique in order to develop the sense of self and identity, selfesteem, confidence, social skills and expression. The songwriting activity is able to take on another level of expression with the function of deeper analysis of lyrics, musical dynamics, and instrumental representations (Bertolami \& Martino, 2002).

Gosine et al. (2017) discuss their project whose mission was to engage, inspire and empower persons aged from 16-21 years old with varying disabilities through community music therapy. The group music therapy sessions consisted of both verbal and non-verbal participants. The technique of songwriting was used in order to facilitate meaningful connection and communication. This sense of connectedness through the shared musical experience of songwriting also promoted a positive reaction to belonging in the group. An insightful aspect of their project was that the effects of the music therapy extended beyond into everyday life for the individual participants (Gosine, et al., 2017). Musical experiences that are shared in this way can 
serve as a medium through which the effects can develop in other areas of a person's life (Stige, 2002).

Collaborating with contrasting levels of ability, individual ideas, including musical tastes and lyrical inspirations will push the traditional sense of a cohesive song. It is important to understand and accept the ideas of participants and to use the activity as a form of community building. The music therapist's role is to contain the songwriting process and to provide an accessible therapeutic experience for everyone (McFerran, 2010; Gosine et al., 2017; Bertolami \& Martino, 2002; Baker \& Wigram, 2005).

\section{Music Therapy Supporting the Development of Play Skills within Special}

\section{Education:}

The interactive nature of music therapy may help provide an environment for assisting the development of play skills with children with intellectual disabilities. Aldridge, Kern, \& Porter (2006) investigated the use of music therapy to improve peer interactions and meaningful play in a playground setting for four boys with Autism Spectrum Disorder. The results indicated that the music therapy adapted environment on the playground facilitated their play and interaction with peers by motivating attraction to the sound and encouraging the use of instruments. The use of song interventions also encouraged the development of meaningful play and interactions on the playground. Using combined interventions such as the use of music therapy alongside an educational approach can improve positive social interactions and decrease inappropriate behaviour (Jung \& Sainato, 2013).

Group music therapy sessions using musical improvisations, have the ability to create a shared musical experience which can transfer to the development of play skills. White (2011), studied the facilitation of group music therapy with children with 
autism who also have learning disabilities and challenging behaviour. The combined approach of a psychodynamic music therapy and behavioural approach provided an opportunity for the children to be social with one another in a safe environment, encouraging the development of play skills and communication. The non-verbal nature of music can support the social interactions of children with complex needs (Caroll \& Lefebvre, 2013). The group environment can allow for moments of connectedness for those who experience isolation in the other aspects of their everyday life. Music therapy facilitates the development of peer interactions and gives a space for relationships to form (McFerran, 2010).

\section{The Relationship of Music Therapy and Intensive Interaction in Special}

\section{Education:}

Intensive Interaction involves vocalising, being responsive to people's facial expressions and body language through imitation, usually within a playful way (Caldwell, 2006). It is a form of communication often found in parent and infant relationships and as natural communicative and social development can provide the basis for interactive skills to develop (Graham, 2004). This type of interactive method of communication and relationship building is a popular tool within special education settings, particularly in the practice of speech and language therapy. How (2014) studied the relationship between concepts of music therapy and intensive interaction in a music therapy centre in New Zealand. The results of the study suggested that there is a relationship between the two and both share the naturalistic processes of 'infant-caregiver interactions' within the environment of music. Each is involved in "fine-tuning to one another's rhythmic, melodic, textural and temporal nuances" (How, 2014, p.3). However, improvisational music therapy facilitates music and it's use of elements in a more complex manner including structure and texture to assist in the therapeutic relationship rapport. The music therapist is relied on for their professional techniques to combine emotion and music within the improvisational process (Loewy, 2004). 
Children with complex needs can face challenges in the areas of sensory perception, sensory regulation or joint attention which are aspects in which humans need in order to relate (Mössler \& Schmid, 2016). For example, children with Autism Spectrum Disorder and their bodily and emotional expressions form and inform relational abilities. Using music that illustrates and adheres to the child's relational resources in a way similar to intensive interaction means that music therapists might have the ability to influence the social skills of children with complex needs and improve therapeutic rapport (Warnock, 2012; Loewy, 2004).

\section{Collaboration with Specialist Services and Teaching Staff:}

Music therapist's working within special education settings are likely to be working jointly alongside other teaching staff and specialist services (Twyford \& Watson, 2008). Teachers, teacher's aides, along with speech and language therapists, occupational therapists, physiotherapists and education psychologists can be seen working collaboratively, using joint therapeutic approaches and consultations with one another. This type of team can give a music therapist's intervention depth and reveal multiple facets of the child's development and goals can be reinforced (Twyford \& Watson, 2008; Bertolami \& Martino, 2002) by working with them through a number of approaches and modalities (Wigram, Pedersen \& Bonde, 2002; Darrow \& Tsiris, 2013).

The understanding of music therapy by other professionals in a special education setting is important to the process of collaboration and consultation (Pellitteri, 2000; Ritter-Cantesanu, 2014, Rickson \& McFerran, 2014). Ropp, (2006) researched the area of the perception of music therapy in an educational setting from an administrator point of view. They found that a lack of understanding of the profession, the music 
therapists' training, and the value of music therapy for the education population was evident. Booth (2004) also investigated the perception of music therapy practice in Victorian special education schools and whether it was understood and valued by the school principals and administrators. The results reflected the need to educate staff members within special schools about the role of music therapy. The role can be misinterpreted by teachers in particular as they confuse the separation of music education and music therapy. The role of a music therapist is to meet therapeutic goals which can also facilitate the children's educational goals (Warnock, 2012).

Goals for children are commonly laid out in 'Individual Learning Plans (ILP) or Individual Education Plans (IEP)' (Ministry of Education New Zealand, 2011) and the actual process of learning for these children through collaborative work within education settings can be valuable for music therapists (Warnock, 2012; Ropp, 2006; Pellitteri, 2000; Ritter-Cantesanu, 2014). Collaborating with professionals working on the 'ILP' can help develop clearer outcomes of music therapy in the educational setting and provide music therapists with a stronger engagement within the multidisciplinary teams (Warnock, 2012).

The advocacy of music therapy to other professionals should not be based on reinforcing status, but rather within collaboration and consultation (Rickson \& McFerran, 2014; Strange. 2017). Collaboration and consultation which takes place within special education settings can include activities such as workshops, seminars, in-services, one-on-one meetings and joint therapy sessions where the professionals work alongside one another assisting and supporting (Register, 2002). An integrated model of collaborating can result in several benefits through utilising own techniques and understanding those of others (Twyford \& Watson, 2008; Laahs \& Derrington, 2016). An example of this can be seen through working with a child with complex communication needs. The use of music therapy techniques alongside the techniques of a speech and language therapist can allow for adaption of professional skills in a 
way that is motivating, natural and therapeutic for the child, and can allow for pleasing and meaningful repetition (Geist, McCarthy, Rodgers-Smith \& Porters, 2008; Talmage, Watson \& Willis, 2014). The benefits are valuable for the participant but also within the professional development of both professionals. The transference of knowledge, understanding of skills and approaches are constructive (Laahs \& Derrington, 2016)

Likewise, Twyford \& Watters (2016) investigated the process of collaborative work between a music therapist and an occupational therapist in developing self-regulation skills in children with neurological conditions. Through the facilitation of music therapy techniques alongside the professional expertise of an occupational therapist they were able to witness positive outcomes in the children. The findings indicated that collaborative approaches of music therapy and occupational therapy may provide children with neurological conditions opportunities to develop self-regulation skills.

Previous research by McDonald (2016) studied the collaboration of music therapists working together in a special education setting. This research highlighted specific benefits and challenges of collaborative work between a registered music therapist and a student music therapist. McDonald found that the collaboration of two music therapists co-facilitating group music therapy sessions allowed for each music therapist to focus more on individual needs of the participants. One moment was drawn upon where one music therapist was able to effectively support a particular distressed participant whilst the other music therapist was able to proceed in containing the rest of the group. Jörg (2017) suggests that there is value in the partnership had between therapist and co-therapist and this type of collaborative work can also be transferred to non-musicians and non-therapists. This is representative of Paul Nordoff and Clive Robbins joint music therapy teaming as Nordoff was a musician and Robbins was a special education teacher (Nordoff \& Robbins, 1977). 
A special education setting requires a music therapist to work closely alongside other specialist services as well as the teachers and teacher's aides. Rickson \& Mcferran (2014) discuss the aspects of a music therapists' collaborative work focusing on a child with profound disabilities. The role of the music therapist was to spend time individually with the child during one-on-one sessions so that then suggestions could be made to the teacher by assisting and supporting that teacher on how to use music in the classroom to build their own relationship with the student. Aiding teachers allows skill of techniques and methods of music therapy intervention to be adapted for the classroom. A large part of this is empowering the teachers (Rickson \& Twyford, 2011; Strange, 2017), giving the teachers tools in which they can facilitate music more effectively to reach the needs of students in the classroom (Aldridge, Kern, \& Porter, 2006). Music Therapy creates engaging and motivating conditions for interactions with others, therefor the need for greater integration of music therapy into the classroom is suggested (Thompson \& McFerran, 2015; McFerran, Thompson \& Bolger, 2016; Munro, 2017; Strange, 2017).

Teacher's aides have a broad perspective of the children they work alongside with and their experiences due to the fact that they move with the child between classrooms, the playground and specialist activities (Aldridge, Kern, \& Porter, 2006; Strange, 2017; Munro, 2017). Consultation from music therapists within a special education context can engage all members of staff but the specific utilisation on the potential of the teacher's aide as a primary advocate for the child can be extremely beneficial (Rickson \& McFerran, 2014).

\section{Summary:}

Music therapy is a valuable element of therapeutic intervention that can help support the needs of children with intellectual and physical disabilities. Music therapy can potentially assist development in areas such as communication, social interaction, 
motor development, emotional \& psychological needs and sensory needs. Interactive music therapy methods can be a way of connecting with participants either verbally or non-verbally where the musical elements are supported by the music therapist in order to develop therapeutic function. To work alongside other educational and behavioural interventions, music therapists are able to combine approaches or enhance them in order to best work within the educational system and met the needs of the children they work with. The action of collaboration and consultation are main features of the professional role within this context as many disciplines work together within a culture of care for the children they support. 


\section{Methodology}

\section{Theoretical Framework:}

This research project is grounded within the theoretical framework of constructivism. Constructivism is a philosophical perspective arguing that knowledge is constructed through personal experiences and situations and that humans are active beings seeking meaning (Mathison, 2005b; Lewis-Beck, Bryman, Futing Liao, 2004). This theory is based on the idea that knowledge is constructed within a context and due to this, it cannot be understood without the understanding of or reference to that context (Edwards, 1999). The qualitative nature of the research question sits comfortably within the theoretical framework of constructivism due to the opportunities it offers me as a researcher to be reflexive about my documenting of work. Reflexivity is a concept that is commonly used within professional practice literature, particularly when the researcher/author is working with uncertainty (D'Cruz, Gillingham, Melendez, 2007; Darawsheh, 2014). Reflexivity within my research relates to carefully interrogating my knowledge, theory and practice and working to make connections between these ideas. It involves critically understanding context and self and their reciprocal relationship (Darawsheh, 2014).

This project investigated how I use musical interactions to collaborate with teaching staff and Specialist Services at a special education school. In doing this, knowledge was constructed by analysing my written clinical data of my own experiences within a cultural and professional context, in turn constructing meaning in order to understand my work. 


\section{Methodology:}

This study involved the use of secondary analysis of data to find out how a student music therapist could use musical interactions to collaborate with teaching staff and specialist services at a special education school. Secondary analysis involves the use of existing data, collected in this context for clinical documentation, and applying to it a specific research question (Mathison, 2005a, Richards, 2009). This research comprised the re-use of my clinical data. This data consisted of material derived from my reflective clinical journal (RCJ). Initially, before the analysis process of my research, I intended to use my clinical notes and RCJ. Once I began the analysis I discovered that the clinical notes ('student progress notes' as referred to by the school) did not reflect on the collaborative nature of my work. The clinical notes solely looked at the progress of individual students in sessions within a concise format of writing. Therefore, I decided to go forward in my research using only data from my reflective clinical journal.

The RCJ comprised of documented informal discussions with teachers and therapy staff, clinical reflections on music therapy sessions, observations and reflections on the day-to-day school context, and professional reflective entries which exhibit personal thoughts and values of my work. The RCJ included data about my work as a music therapy student that was rich, detailed and diverse. This created enough data to be thoroughly analysed in order to investigate how I used my music to collaborate. An example of an entry from the RCJ is included at Appendix 1 of this study.

The use of this data was examined through the process of thematic analysis. Thematic analysis is a method for identifying themes within data (Braun \& Clarke, 2006, Richards, 2009). By re-analysing my written data, I identified areas that linked to the research topic (musical interaction and collaboration), selected and coded these (see Appendix 2) and then began to group the codes that appeared to connect. From these 
meaning groups, I was able to identify themes that for me created insight and meaning from the clinical work (see examples at Appendix 3). These themes were then used to reflect and build answers to the research question.

\section{Research Method and Design:}

Through secondary analysis, this research constructed meaning by re-analysing clinical data to draw out common themes that informed the research. Thematic analysis is a foundational method for qualitative analysis (Mills, A. J., Durepos, G. \& Wiebe, E, 2010, Richards, 2009, Braun \& Clark, 2006). Thematic Analysis is defined as 'a method for identifying, analysing, and reporting pattern (themes) within data' (Braun \& Clarke, 2006, p. 79). A theme identifies accounts about the data in connection to the research question and serves as a patterned response or meaning to the data. As this was my first exploration of research at this level of inquiry, I wished to use thematic analysis as it is deemed a flexible approach to data analysis (Braun \& Clark, 2006, Richards, 2009). This approach enabled a rich and detailed understanding of my clinical work in a way that is also beneficial as a researcher gaining core skills in conducting qualitative analysis.

I gathered clinical data from my practice as a student music therapist within a special education setting. This data included written documentation gathered from my RCJ. Even though I was able to obtain access to audio and visual resources for clinical observations, I preferred to not use these categories of data in my research. I focused on the personal reflective written documentations of my clinical practice. Once the clinical data had been accumulated, the secondary analysis process commenced. 
I began with familiarising myself with the data. The data collected through my clinical practice was read repeatedly in a way that I began to search for meaning and ideas of patterning as these identifications were shaped as I read. I began generating initial codes from my data that were then used to systematically sort the entire data set. Searching for themes followed which re-focused the data in a more extensive level of themes. This was the process of analysing my codes and considering overarching themes formed by them. These themes then contributed to a thematic map created through the process of repeated reading of data. The themes were further reviewed, refined, defined and named in order to provide clear understanding of the data.

\section{Research Ethics}

I, the researcher and music therapy student have provided the clinical data for this research project. Due to the secondary analysis of personal material that is selfreflective, no direct participants were being studied. I abided by the Code of Ethics for the Practice of Music Therapy in New Zealand (2012) and Victoria University of Wellington Human Ethics Policy and Guidelines. Ethical approval for this type of study has already been gained through the music therapy programme leaders at the New Zealand School of Music. Careful consideration has been taken into account of the Treaty of Waitangi and the affects that this research may have on New Zealand Māori. This research worked to build collaborative relationships with staff and students, and from my workshop training at Victoria University with postgraduate learning adviser Māori, I learnt the importance of conversation and collaboration with others as a feature of research with Māori. This study lends minimal threat to the Treaty of Waitangi and New Zealand Māori, though considerations on the matter have continuously been reviewed throughout the duration of the research project as a means of reducing any risk.

Informed consent was obtained by parents/guardians of the music therapy participants who may have been indirectly involved in the vignettes that I have included in this 
research. (See Appendix 4 for examples of the information sheet and consent form.) The special education school where my placement took place also formally agreed to the research project being developed within their school community and for the data to be analysed and presented in an exegesis. Even though this research is focussing on self-reflective clinical notes and written material, it is important that action is taken for the protection of those indirectly involved in the research process. No real names of participants have been used in any of the research as a means of protecting ones' identity. The school principal has given formal consent to the use of the schools' name.

On completion of this research project and acceptance as fulfilment of a master of music therapy degree at the New Zealand School of Music, the research will be published in the Victoria University of Wellington library, and where appropriate I would seek to disseminate through conference presentation or relevant journal articles. All data collected from this study will be held for a period of 5 years in a secure setting overseen by supervisors at the NZSM, Victoria University of Wellington and later destroyed once the period has elapsed. 


\section{Findings}

\section{Introduction:}

The findings are presented within five themes. These themes have been derived from the analysed raw data of my Reflective Clinical Journal (RCJ). The five themes being presented do not appear to have a hierarchy and therefore are in no particular order. They also appear to relate to each other and to flow onwards. They are presented in the following diagram.

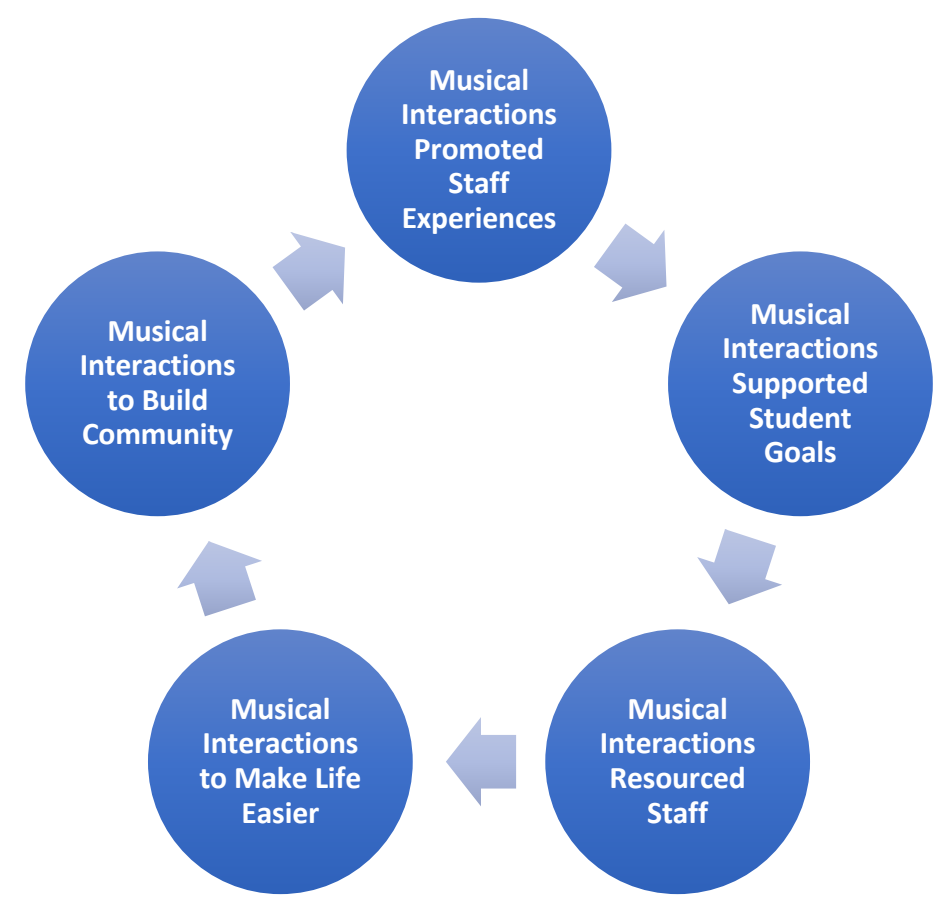

They represent a comprehensive overview of the musical interactions shared amongst teaching and specialist services at the school.

At the beginning of each of the five sections, I have an itemised the codes that are included in the section. Each theme is then expanded and accompanied with some description and examples of raw data from my RCJ. Clinical vignettes are also 
included at times to provide further understanding of themes within the context of my clinical practice.

\section{Musical Interactions Promoted Staff Experiences:}

Codes developed in this theme:

- Teaching staff modelling for student in group music therapy.

- Teaching staff as participants during improvisations.

- Supporting teaching staff to be musical.

- Musical improvisations to help inform teaching staff of students.

- Musical improvisations to connect teaching staff and students.

- Intensive interaction/vocal improvisation supporting relationship building.

- Co-facilitation with music therapy team.

Making music together or being involved in music therapy sessions appears to have promoted staff understanding of the importance of being a participant alongside the students, modelling and encouraging students whilst giving time and understanding of different levels of participation. During group music therapy in the classroom, I was able to inform teaching staff that instead of relying primarily on verbal and physical instructional guidance to motivate and encourage student participation, one can use the music to elicit a natural response to participate. I supported teaching staff to interact with students in this way by helping them to remove their initial expectations of how the musical activity/interaction should look or sound like. Holding expectations can limit the spontaneity in the therapeutic process. Instead, teaching staff were participants alongside students in the musical interactions. Modelling ways one can move and be musical by encouraging students to get 'inside' the music. Alongside modelling, is the act of giving plenty of space and time for students to 
contribute. That space given can allow a student time to fill it by genuinely initiating an autonomous and meaningful response, however big or small.

The teaching and specialist staff were informed by making music directly with students and especially by witnessing them within a different approach and environment. These meaningful experiences often transferred into moments of connection and relationship-building between staff and students. An example from the data showcases an informal moment when I was in the playground during lunch time, playfully interacting with a young girl with Autism Spectrum Disorder (ASD) and a teacher. Supporting the interaction together, I imitated the students' movements, allowing the student to lead. Highlighting certain rhythms and sounds made from our bodies or playground equipment. This turned into a playful and energetic game. I facilitated musical vocalisations that matched, held and responded to her nonverbal, vocalising sounds of communication. The teacher seemed to be comfortable to reaffirm some vocalisations by mimicking responses back to the young girl. This example from the data conveys a brief and meaningful moment where the experience of this informal musical interaction allowed for relationship-building and connection between staff and student in a genuine way within a casual environment.

Using musical vocalizations in the playground with a young autistic girl alongside a teacher. Connecting with her in a casual environment. Using her movements, gestures and vocalising sounds and meaningfully imitating, mimicking and reaffirming them. Supporting the interaction. (25.07.17 - Raw data from RCJ).

Another example of enhancing staff experiences was co-working between the music therapy staff. I felt extremely fortunate to be a student Music Therapist working alongside a very experienced registered Music Therapist. Together, we mutually supported one another by containing moments in sessions, giving guidance and cocreating meaningful musical interactions which developed my own work as a student 
and the professional relationship further. An example of this collaborative work is conveyed through a moment of co-facilitation where I lead an individual session whilst the other music therapist supported.

The music therapist and I collaborated on a session with X. During a playful activity on a chair, the other music therapist played with the young girl whilst I accompanied their interactions and movements on the piano. Imitating their movements through the music, changing dynamics to represent mood and colouring to create atmosphere. Vocal work was also used to mimic and imitate the young girls' vocalizations with the other music therapist. The other music therapist would also model whilst I accompanied. (28.06.17 - Raw data from $R C J)$.

The experience of having a second Music Therapist to support the musical interactions meant that I was able to feel more committed to being 'in the moment' and 'in the music' alongside the student participant.

\section{Vignette:}

A staff professional development workshop facilitated by myself and co-Music Therapist. Workshop conducted around the theme - "The experience of making music together influencing our understanding of music therapy practice".

The staff all held a stone in their hand which they picked from a bowl in the middle in the circle. With a strong but calm voice, I lead the staff to pass the stone from their hand into the hand of the person seated next to them, thus creating a large simultaneous directional movement of stones being passed around the circle. "Listen to my heartbeat, listen to my heartbeat, beating out the rhythm of my soul..." we sang 
as we passed our stones to one another. Around, around, around...Around, around, around until the singing and movement tempered to a soft end.

The staff talked about how the stone passing focused them, how it was easy to follow and join in. "I didn't feel singled out because we were like one big machine" - "Yeah it was hypnotic, right? It was something like a chant", they divulged amongst each other. One pointed out how he enjoyed choosing his stone and waited in anticipation as it returned to him from around the circle.

With an array of instruments - some melodic, some percussive. Instruments that created soundscapes of atmospheric timbre and others interesting enough that one didn't know quite how to play the thing. The group started to play one by one as it went around the circle. Once a full circle had been made and unified the players, one by one they would drop out. "Well that was definitely original!" one woman exclaimed followed by a burst of laughter and eyebrow raises from the group. "Yeah it was a bit messy and disjointed I'd say" - "I wouldn't call it cohesive" - "Those chimes were really noisy for me, I struggled to get past the sound" - "Oh yeah, but it was fun! I loved letting loose and hearing the different sounds as people joined in and then dropped out of the playing" - "It was a bit out of my comfort zones at times, if I'm honest”. They all casually discussed amongst themselves.

I noticed that a woman had her eyes closed during moments of the improvisation. When approached about it, she said that she was closing her eyes so that she could listen properly and not be distracted by what was happening in the room. A mechanism for escaping so that she could be more in the music. Taking the lead of the participant, I suggested to the group that we conduct another improvisation, though this time with our eyes closed. One tap on the shoulder means one can begin to play, second tap means stop. They all agreed to the activity and proceeded. 
Once the improvisation had ended, the staff members sat there in silence. Some looking down to the floor, some remained with their eyes closed for a moment, whilst others exchanged calm and reflective looks to one another. "Wow, that was different" - "Yeah, that one was far more cohesive and sounded almost tribal" - "I think I felt more confident and comfortable playing with my eyes closed" - "I still couldn't block out those chimes though" - "Ha! I had to stop myself from getting up to dance. I was telling myself to stay in my seat but the music was motivating me to move. However, I wish I did. I just wasn't sure if I was allowed" - People's comments met with nods and "aha's".

The vignette showcases how staff were able to gain insight into how one may experience a group music therapy session by actively being participants themselves. The musical activities and the staff reactions and comments conveyed that people appreciate music differently. One may enjoy the musical interaction whilst others may find the music too loud and overwhelming such as the individual who had difficulty with the sound of the chimes. Therefore, acknowledging that shared experiences in music may be valued or understood conflictingly.

Their comments from the music making also tell us how important the music is. By closing their eyes, staff members were immersed deeper into the musical experience and seemed to focus more sensitively on the musical elements and interactions had with one another's sound. Witnessing how one staff member had to stop herself from getting up out of her seat to dance because the music was motivating her to do so. This is a clear example of music eliciting a response that is genuine. How the music and its elements as well as given space and time can 'call' someone to initiate an action, a feeling or sound. 
Lastly, what is important is how the musical interactions transferred into moments of connection and relationship-building. Staff members spoke about feeling like a 'machine' during the stone passing activity and they felt part of a larger body rather than being singled out or separate from one another. Members of the group seemed to feel proud of their music and were interested in what others were doing. Also, how another's music making influenced their own. The musical interactions motivated people to laugh together, to listen and acknowledge one another. Naturally encouraging positive moments of interaction, connection and relationship building within the group.

\section{Musical Interactions Supported Student Goals:}

Codes developed in this theme:

- Supporting student goals with musical improvisations.

- Supporting the learning agenda.

- Music supporting play skills.

- Assisting SLT and teaching staff in musical ideas.

- Collaborative songwriting with SLT.

- Musical improvisations to connect teaching staff and students during the learning agenda.

Music was able to support student goals by corresponding to the classroom learning agenda and Individual Learning Plans set out by the teaching and specialist staff. The facilitation of musical interactions assisted teaching staff in connecting with the students during individual learning times, either by complementing the task at hand, encouraging student participation in the activities and motivating engagement for the 
teachers as well as the students. An example from the data highlights a moment when I improvised sung melodies and instrumentation whilst a young girl interacted with her teacher during a sensory activity.

I sang and played the guitar to a young girl who was experiencing sensory time with the teacher aide. I matched the mood and textures of the material to the sounds by changing dynamics, vocal colours and breathing techniques. (13.06.17 - Raw data from RCJ).

This therefore, expanding the experience of the activity and interaction for the student and teacher.

Another moment in the data was conveyed when I interacted with a young student who was placed in a hoist/sling to encourage gross motor movement. In order to assist the teacher's efforts, I used voice and guitar to motivate the student to walk across the room. The musical interaction seemed to stimulate her to move her legs by providing a solid rhythm that could match her gait. Added musical techniques created developments in encouragement via anticipatory anacrusis and building crescendos left with space. The music also seemed to animate the teacher which actuated the inclusion of further playful elements to their interaction. Therefore, creating an environment that supported the students' goals but also one that motivated and engaged the teacher in a means that promoted connection between staff and student.

Original compositions promoting play-skill development in students were created through collaboration with teaching staff and specialists. Giving teaching staff a musical medium for supporting students in a way that was fun, genuine and a natural response to play was perceived as particularly valuable. These original compositions complemented the work of the speech and language therapists, an occupational therapist and certain teaching staff who were involved with the promotion of play skill development in certain classrooms. Play scenarios and play communication work 
were integrated into group music therapy sessions through semi-structured musical improvisations and activities with original compositions and adapted songs. The play skill songs were used within informal settings as well. These situations taking place in the classroom during periods of free time or in the playground. By collaborating with teaching staff and specialists, I was able to gain understanding of how to appropriately and effectively combine approaches and common aims. In order to work effectively together so that the musical interactions could reach the students' goals.

Discussion with a SLT about how my work can complement her work with helping develop students' positive play. We decided on how her play scenarios or play communication work can be adapted to my music therapy group session through structured improvisations, action songs, songs with lyrics about play. (23.05.17 - Raw data from $R C J)$.

Example of an adapted song for play skills:

This song was created with the guidance of a speech and language therapist on appropriate functional language for developing play skills. The music therapy activity was facilitated by using the lyrical and musical structure of the song to encourage the students to invite a friend to play with them on an instrument of their choice.

\section{Can I play with you?}

Adapted by Devin Brooks from Linda Perry's composition "What's Up".

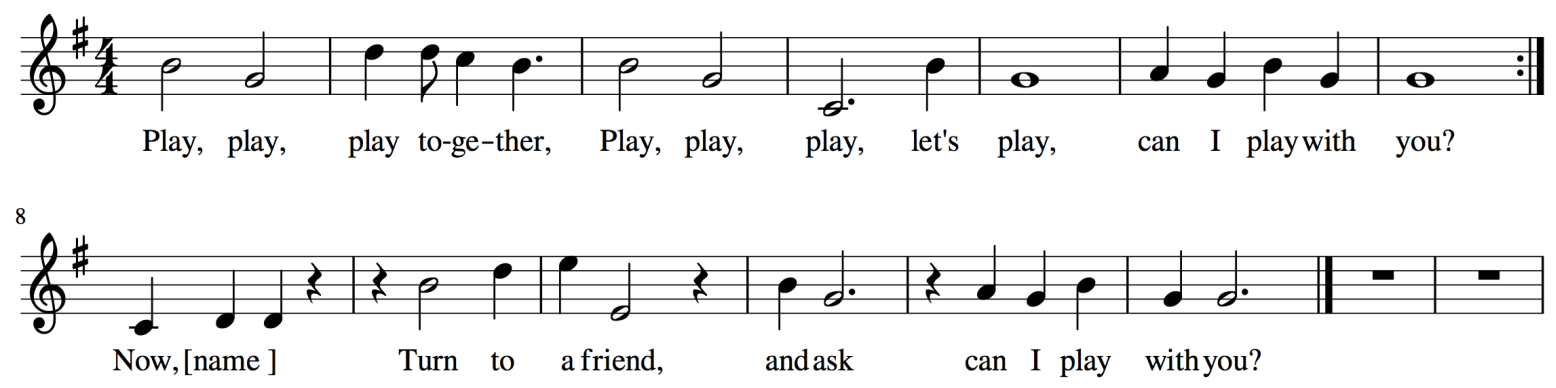

(Perry, 1993). 
Vignette:

A group music therapy session in the classroom. This vignette will hopefully provide insight and clarity into the types of musical interactions and techniques used in order to support the teachers' goals for the students. This classroom had a particular focus on development of play skills through working on turn-taking, listening and responding to one another. An example of the original composition used in this vignette is shown below.

The students had chosen their instruments that they wanted to play and had found a space in the room for where they would like to be. Some students sat together in pairs, some in corners of the classroom, whilst one had taken sanctuary under a table. Teachers were invited to choose an instrument and a place in the room as well, so that they could be participants alongside the students.

I played an upbeat, jig style tune on the recorder as a melodic framework for the activity. The students all played along with their instruments as I hopped and 'jigged' my way around the room. The music came to a halt as I stopped by a teacher aid and the students followed by stopping as well. Without words, I initiated a message with my recorder to the teacher aid, then waited. The teacher raised her tambourine and gave it a shake. I responded back in a musical conversation; using the teacher as a means for modelling how the activity and interactions will play out. After a short moment, I began to play the jig-like melody again, whilst dancing around the room and this seemed to motivate the students to recommence playing.

I stopped at a student who was playing with a rain stick on the floor. The other students had silenced and look over from their spaces, intrigued to see what was 
going to happen. At first, the student seemed a little confused of the expectation of what to do. Though, he began to move his stick and then watched me for a response. I played a descending melody on the recorder which complemented the falling sound of the rain stick. It didn't take long for the student to realise that he was in control as much as it was mutual. The musical conversation between us began to be rather playful by stopping and starting abruptly and teasing one another in reactions of anticipation, smiling and laughing. I contained the interaction by matching and responding to his musical expressions and body language. This was done by repeating given rhythms or accents, acknowledging dynamic changes and by being alongside him on the floor at his level. The student listening and connecting in a conversation without words.

Example of the original composition used in vignette above.

\section{Play Jig}

Original Composition by Devin Brooks
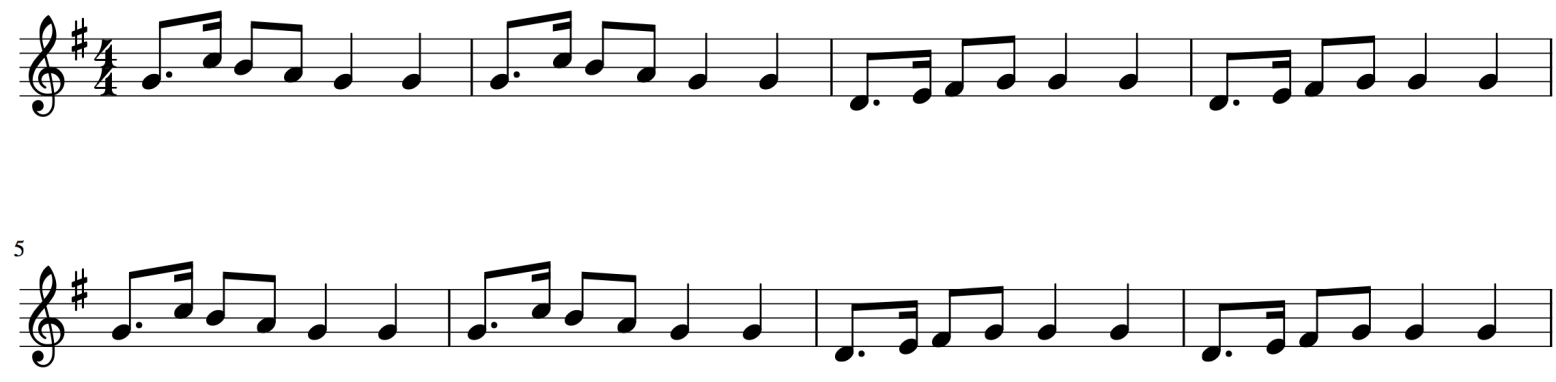

9

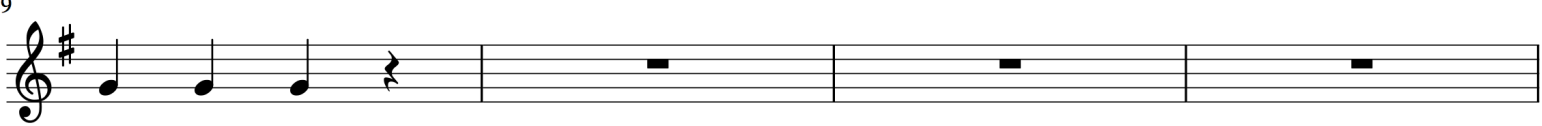

This example shows an originally composed song that was used as a musical improvisation framework in order to encourage students to play along on their instruments. What is portrayed on the score is the main structured theme that was used 
reoccurring throughout the activity. Musical space was given in-between for musical conversation improvisations.

\section{Musical Interactions Resourced Staff:}

Codes developed in this theme:

- Supporting teaching staff to be musical.

- Giving ideas to staff on how to facilitate music in the classroom.

- Resourcing the teaching staff with musical materials.

- Transference of musical activities to teaching staff.

Collaboration between music therapy and teaching staff gave support for teachers to become facilitators of music in the classroom. This happened by encouraging teacher confidence and comfort to "be musical" and also resourcing them with musical materials and activities. It included motivating and supporting them to sing along, to lead and hold group music-making activities, as well as being genuine in their musical interactions with students and teacher aides. On one occasion I supported a teacher on ways one can conduct a warm up activity for a music and dance session in the classroom. I assisted by helping choose appropriate repertoire that would motivate students to move and guided the teacher on how to accentuate the genuine movements made by participants. By witnessing participants naturally moving to music, I brought attention to their movements which were imitated for the group to follow. "Look, [name] is moving their fingers, let's all move our fingers too". Therefore, generating a more student focused, student lead warm up activity. 
Resourcing teaching staff with physical material also provided them with the means to facilitate musical activities in the classroom. Within one situation, songwriting was conducted during a music therapy session alongside students and teachers. Through collaboratively composing the songs musical and lyrical components together, the teachers were resourced with material that could be practiced and sung during the daily classroom routine. In order to support the teachers to be facilitators of music in the classroom, I assisted in providing recorded instrumentation and video of the composed song. This made the process of singing the song in class much more accessible by having grounding resources to follow.

I recorded the instrumentation and hummed the melody in a video recording for the teachers to have a resource to go by. Teaching staff to help prepare the students for the performance. (13.06.17-Raw data from RCJ).

Focus was given to demonstrating how to tailor music specifically to meet and respond to students during challenges moments, as well as how to incorporate meaningful musical experiences within the classroom routine. It was witnessed in the data that teachers were using material from music therapy sessions in order to alleviate moments of elevation or distress in the classroom.

She found it very good. She said that she used 'listen to my heartbeat' in class as a mechanism for calming the students when they were too elevated. (20.06.17 - Raw data from RCJ).

Resourcing the teachers to become confident facilitators of musical activity was conducted by supporting the teacher to be an active, leading participant in the sessions. By presenting opportunity for teachers to model and respond to the group during musical interactions, the teachers were able to gain skills of facilitation. Teachers' witnessed how musical elements such as rhythm, tempo, vocal colouring, dynamic changes and timbre can be used to gain attention, to focus, to calm, and bring students together. 
Teachers were also supported on how to adapt activities experienced in music therapy sessions for the classroom. Teaching staff frequently do not have the time during the daily routine in class to resource themselves with appropriate equipment and may not have the confidence and skills to play an accompanying instrument. Ideas were given to a teacher on how to produce a musical improvisation activity in the classroom without instruments. Suggestions were given on the use of prerecorded music and body percussion as well as movement and dance as a means of expressing one's self musically. Highlighting the value in the interactions that the activity invokes, rather than the musical display was important. I was able to demonstrate that demonstrating that facilitation of musical activities does not require substantial musical skill and knowledge for them to be meaningful and useful.

Musical Interactions to Make Life Easier:

Codes developed in this theme:

- Using music to see if we can lend a hand to difficult situations.

- Musical improvisations to connect teaching staff and students.

- Supporting moments with staff by facilitating music/singing songs.

- Songs to assist transitioning.

- Helping regulate students.

- Music for calming.

- Being alongside staff and students through music, during the little moments.

Creating musical interactions between teaching staff and children were found to support the little moments when life at a special education setting can be challenging. 
Music was able to support difficult situations by being alongside students who were experiencing distressing episodes, and stepping in to help calm and ease situations. The data illustrates the attention given to a young student who was experiencing a moment of distress outside of the classroom.

The boy was lying on the ground and continuously banging his head against the concrete. The teacher said it had been going on for a while and didn't know what else to do except wait for him to calm down so then she could move him back inside. I grabbed my guitar and went over to the boy. I stood next to him and began to softly play. (27.06.17 - Raw data from RCJ).

The use of music was able to assist the student as well as the teacher in this instance. I used instrumental and vocal improvisation to support the teacher in 'lending a hand' to the difficult situation. The musical interaction with the student was calming by softly picking the guitar strings in a $3 / 4$ rhythm which represented the rock of a lullaby. The students' vocal pitches were matched and were imitated in soothing melodic phrases which grabbed the attention of the student. Responding to the state and nuances of the student through musical dynamic changes. This musical interaction seemed to aid in regulating the student to a calmer state where the teacher was then able to assist the student back to the classroom.

Musical interactions were conducted flexibly in settings throughout the school environment in a warm, genuine and often informal manner. This provided aid during times of transitioning, assisting routine tasks, as well as affirming staff and student connection and wellbeing. By being an active participant in the everyday life of the school, I was able to meet the needs of students and staff in informal settings such as in the playground or in the hallways. By making myself accessible, I was there to appropriately assist staff and students. The data highlights multiple times where music supported transitioning within the school day routine. This was through musical interactions helping prepare and motivate students to return to class after lunchtime. 
Music matched gait for those who had difficulty walking, encouraging and motivating their movements through grounding rhythms, anacrusis and crescendos. Song lyrics were improvised within interactions with teachers and students as they walked back to the classroom. Creating a playfulness that reinforced a positive relationship between staff and students as well as giving instructional language which supported the transition.

\section{Musical Interactions to Build Community:}

Codes developed in this theme:

- Musical improvisations to connect teaching staff and students.

- Musical activities supporting play with staff and students in the playground.

- Supporting teaching staff to be musical in everyday situations.

- Supporting moments with staff by singing songs.

- Singing songs to encourage interaction.

- Musical improvisations showcasing meaningful moments with students.

- Group music therapy supporting teacher and student relationships.

- Informal musical interactions.

- Teachers as participants, being part of the group.

Music was used to bring people together and to build community. Musical moments, in mostly informal settings, encouraged connecting with one another. These musical interactions were conveyed through impromptu singing amongst staff in the staff room and classroom. 
During staff flu vaccinations, I played music on the guitar and sang a couple of songs to pass the time as we all waited in observation after the injection. The staff came together, singing, waving arms in the air and having a laugh. (16.05.17 - Raw data from RCJ).

Music was the tool encouraging connection and relationship building during informal settings. Singing songs together in the staff room transferred into conversations between one another. Interpersonal discussions about song choices and reminiscences derived from the music material. This seemed to create an environment where people were perceived to be relaxed and enjoying their time together. The facilitation of the impromptu group singing involved familiar song choices that were carried along by prompting. The first few words of the song were the prompts that invited staff members to join in and be made aware of what to sing. Crescendo's and musical pause helped create building of energy and motivation to join in. Movements such as group clapping and swaying of arms in the air formed an atmosphere that was energetic and fun.

Singing songs informally for teaching staff in the classroom brought teaching staff and students together. Songs that were chosen by the teaching staff were facilitated intimately on the guitar after music therapy sessions. The musical interactions transferred into moments of connection and relationship building by allowing a moment and space for teaching staff to relax and have some fun amongst themselves and with students. The music often encouraged people to move and dance with the students, to be playful and have a laugh. Some sang along or chose to sit and enjoy the music whilst filming it on their phone cameras, capturing to enjoy the moment once again at another time. This type of informal musical experience seemed to give opportunity for teaching staff to share aspects of themselves through song choices. This was shown either through perceptive reflections of their personalities as well as song choices that conveyed particular meaning to them. The singing seemed to bring colleagues and students together, thus building a feeling of community. 
I sang a song for the teaching staff in room X. They were eagerly waiting for the song this week. Taking turns to take the students to the toilet before morning tea time. It is nice to see them relaxed and this transfers to the students who can see them smiling. (13.06.17Raw data from $R C J)$.

Music interactions supported staff and students to be musical with one another in everyday situations either in the classroom, playground or in the hallways. In these communal moments, improvised songs and musical interactions were used to encourage spontaneous responses amongst one another. This invited people to sing, dance or share a reciprocal musical connection. The music establishing a seemingly meaningful and genuine communicative experience. These moments of connection through music helped to develop the community spirit amongst the whole school population. It allowed a space where students could interact with staff in a musical and playful framework. Staff shared aspects of themselves and learnt about other people (children and adults) as they shared the experience of making music together.

Vignette:

This short vignette portrays a moment after a group music therapy session when the students of this particular classroom go to the bathrooms to wash up and get ready for the transition into lunchtime. This vignette provides insight into an instance where music informally created a sense of community during the routine activity.

Seated in a circle, the music therapy session had come to a close. The teacher warmly remarks on how great everyone was and gives me a kind nod. The smell of food starting to waft in the air of the classroom, I can sense the students anticipating their 
lunches. "Right, time to wash our hands and get ready for lunch", the teacher announces. This was met by some vague faces and slight groans by a few. "Now, we need to be walking and not running down to the toilets".

I pick up my guitar and start to play the chord structure of a familiar song previously sung in the session. I begin to sing, adapting the lyrics to "Walking, walking, walking, walking. Walking, walking, walking, walking to the toilet. Walking to the toilet". The teaching staff and students laugh and smile at one another, seeming to think that it was rather silly. They all stand up and start walking out of the classroom and into the hallway. I follow with my guitar and sing alongside them as they head towards the toilets. The song starting to sound on the voices of the students and teaching staff. Soon we are all singing - "Walking, walking, walking, walking. Walking, walking, walking, walking to the toilet. Walking to the toilet". Giggling is heard over the top of the music and I observe students walking in time with the beat, moving their bodies to the music and some holding hands with other students. The teacher now confidently singing and interacting with the students in a playful manner by giving big expressions.

During the musical interaction down to the bathrooms, other teaching staff and students joined us in the hallway. People interacting with one another in an informal jovial manner, having a laugh at the ridiculousness of the song but seeming to enjoy the experience. Some students walking past me, taking an opportunity to brush their fingers over the strings of the guitar, actively participating and engaging naturally and genuinely. 


\section{Summary of Findings:}

The findings drew upon moments when musical interactions collaborated with teaching staff and Specialist Services. These moments were derived from the raw data analysed from my RCJ. The codes that developed during the analysis process formed five themes which showcased the different ways in which the musical interactions were facilitated within the context of the school.

From the five themes, we are informed of how musical interactions promoted staff experiences of music-making with others. The experiences gained supported staff to be musical as well as convey the importance of being an active participant alongside students in group music therapy sessions. Co-facilitated sessions working alongside another music therapist gave me the experience of feeling supported within the therapeutic process. I was able to feel more committed to being "in the moment" and "in the music" as a music therapist. Music was also able to support student goals by corresponding to the classroom learning agenda and Individual Learning Plans set out by the teaching and specialist staff. The facilitation of musical interactions assisted teaching staff to connect with the students and encouraged student participation in the activities and motivating engagement for the teachers as well as the students.

The findings displayed how musical interactions gave support for teachers to become facilitators of music in the classroom. Support was given by encouraging teacher confidence and comfort to "be musical" and also resourcing them with musical materials and activities. Also, musical interactions with teaching staff were found to support the little moments when life at a special education setting can be challenging. Music was able to support difficult situations by being alongside students who were experiencing distressing episodes, and stepping in to lend assistance to teaching staff to help calm and ease situations. Lastly, the findings highlighted how people were brought together through music. Musical moments, in mostly informal settings, 
encouraged connecting with one another through singing songs and making music together. These moments of connection through music helped to develop the community spirit amongst the school population. 


\section{Discussion}

The findings of this research have derived a few points of interest which deserve further discussion. Firstly, what I found surprising from the research findings was the theme "Musical interactions to make life easier". During the analytic process, I came across codes in the data that connected to the notion of lending a hand during challenging or distressing moments. Assisting during these moments supported connecting amongst staff and students as well as a sense of community and trust (Ansdell \& Pavlicevic, 2004).

Music used for connecting and building of relationships were strong codes derived from the data. The findings helped me to recognise that I enjoy and see value in working within a style that supports communities. This is something that I had not included in the literature. Whilst gathering and forming the literature review component of the research, I did not have intentions of searching for written work documenting community music therapy approaches. Looking in retrospect, I realise now that my initial viewpoint of how I envisioned my collaborative work, was in fact, rather naive.

Community Music Therapy cultivates musical community wherever the therapist and clients find themselves (Ansdell, 2002). I think this is particularly true to the informal musical interactions I found myself in within the school setting. Music was able to meet students and staff outside of the therapy room and classrooms, providing support within casual settings such as the playground, hallways and staff room. These informal musical interactions enabled meaningful connections with the school community. I did not envision that these types of interactions would be so prevalent in my research findings. The detailed examples from my own findings and further 
support by those in the field highlight the benefits that music can bring to a community context.

First, music's sound and energy naturally leaks out from its source. Anyone who's ever tried to soundproof a music therapy room knows they're on a fool's errand. Music is not designed for privacy or containment - it naturally reverberates, permeates, goes through boundaries and walls. And in doing so it calls to others, attracts, gathers, connects people together. It creates community (Ansdell \& Pavlicevic, 2004., pg. 16).

This conveys how valuable a community focus is in detailing a music therapist's role within this setting. Through a community lens, music therapists are able to work across contexts which can provide in a flexible approach for harnessing connection and relationship building (Davidson, 2012; Stige \& Aaro, 2012; Gosine, Hawksley, \& Quinn, 2017; Aigen, 2012).

The findings highlight attributes of how musical interactions can support staff to be musical. Within these interactions, I was able to provide skills and help develop understanding of music making. The notions on different levels of participation and how one can be confident within their genuine responses to music are elements conveyed in the data. The experience of collaborating with other disciplines informs us of the skills music therapists bring to this type of collaborative context (Munro, 2017, Twyford \& Watson, 2008; Rickson \& McFerran, 2014; Laahs \& Derrington, 2016). By being supportive alongside staff during moments of music making one may perceive a sense of empowerment gained as their confidence builds within musical situations (Watson, 2017; Rickson \& Twyford, 2011; Rickson \& McFerran, 2014). This can help create a shift from teaching staff identifying as assistants or an extra person in the room to them being interactive participants alongside the students (Strange, 2017; Jörg, 2017). 
Research on collaborative practice is increasing, and it was pleasing to learn about Laahs and Derrington's (2016) study influencing the way students are trained to be aware of the potential to collaborate early in their professional lives. Likewise, reflecting on my work as a student helped me to understand the importance of knowledge and understanding of other disciplines. It is valuable for music therapy students to experience collaborative work during placements to further develop and broaden their professional skills.

The limitations of this research relate to how I was able to develop the qualitative design. Whilst this was completely my intention and desired approach, the design provided findings that derived from my own very specific perspective. The use of a single data source additionally contributed to this limitation. If I was to embark on future research, the use of one or two extra data sources and other people's perspectives contributing to the analysis would create findings with more detail and richness. The research is therefore taken from a rather narrow point of view regarding collaborative work. Due to this, the research would be difficult to support collaborative work in a wider sense regarding the field of music therapy. Instead, the research serves to give insight into how a student music therapist may work and use music collaboratively within multifaceted domains of a special education setting.

I must make it clear that I am a student music therapist currently in my training. I am in no way delivering information in this research that should be perceived groundbreaking or new to the field of music therapy. It is however, important to respect the idea that being a student, these findings gave insight into how I understood my work. Therefore, it revealed a lot to my own learning. This type of research is practice based research, which in this case, informed me of the process and journey I am undertaking as a student music therapist in my training. I can reflect on this experience and feel confident as I continue on my path to become a music therapy practitioner. 


\section{Conclusion}

This research set out to investigate how I used musical interactions to collaborate with teaching staff and specialist services at a special education school. This inquiry of research derived from the context of being a student music therapist on placement learning to navigate in a collaborative team within a new setting. I was intrigued as to how the "music" collaborates with the staff at the school as well as discovering how I facilitate those musical interactions in a meaningful way.

Through secondary analysis of my reflective clinical journal notes I was able to explore how I used musical interactions to collaborate. Specific codes from the data were drawn out and then compiled into themes. Five key themes resulted from the findings, which are captured again here.

From these five themes, we were informed of how music interactions promoted the experience of music making together with others. The experiences gained supported staff to be musical as well as convey the importance of being an active participant alongside students in group music therapy sessions. Music was also able to support student goals by corresponding to the classroom learning agenda and Individual Learning Plans set out by the teaching and specialist staff. Music motivated and engaged students and teachers to support these goals and classroom activities.

Musical interactions gave support in resourcing staff to become facilitators of music in the classroom. This was achieved through assisting in musical materials as well as giving teaching staff the tools and confidence to be musical alongside students. Musical interactions with teaching staff were found to support the little moments 
when life at a special education setting can be challenging. I was able to use music to lend a hand during distressing moments by stepping in to assist in calming and easing situations. Lastly, musical interactions perceived to build community within the school. Music making and facilitation of music in mostly informal settings seemed to support connecting and relationship building between students and staff. Highlighting these processes was beneficial to me as a student practitioner and will inform my work in future professional life. I hope it will also be of benefit to other students and music therapists in related contexts. 


\section{References}

Abbott, E. A., \& Sanders, L. (2013). Perspectives of paraeducators on collaboration in music therapy sessions. Canadian Journal of Music Therapy, 19(1), 47-65.

Aigen, K. S. (2012). Community Music Therapy. The Oxford Handbook of Music Education, 2.

Ansdell, G; Pavlicevic, M. (2004). Community Music Therapy. London; New York.: Jessica Kingsley Publishers.

Ansdell, G. (2002). Community music therapy and the winds of change: A discussion paper. Voices: A World Forum for Music Therapy, 2(2).

Baker, F., \& Wigram, T. (2005). Songwriting: methods, techniques and clinical applications for music therapy clinicians, educators and students. Jessica Kingsley Publishers.

Bertolami, M. D., \& Martino, L. A. (2002). Music Therapy in a Private School for Visually Impaired and Multiply Handicapped Children. Voices: A World Forum for Music Therapy, 2(1). http://doi.org/10.15845/voices.v2i1.69

Booth, R. (2004). Current practice and understanding of music therapy in Victorian special schools. Australian Journal of Music Therapy, 15, 64+.

Boxil, E. H., \& Chase, K. M. (2007). Music therapy for developmental disabilities. Austin, Texas: Pro-Ed.

Braun, V., \& Clark, V. (2006). Using thematic analysis in psychology. Qualitative Research in Psychology, 3(2), 77-101.

Brunk, B. K. (1999). Music therapy: another path to learning and communication for children in the autism spectrum. Arlington, TX: Future Horizons. 
Bruscia, K. (1987). Improvisational Models of Music Therapy. Springfield, Illinois, USA.: Charles C Thomas Publisher Ltd.

Caldwell, P. (2006). Speaking the others language: Imitation as a gateway to relationship. Infant and Child Development., (15), 275-282.

Carroll, D., Lefebvre, C. (2013). Clinical Improvisation Techniques in Music Therapy. A Guide for Students, Clinicians and Educators. Springfield, Illinois, USA.: Charles C Thomas Publisher Ltd.

D’Cruz, H., Gillingham, P., Melendez, S. (2007). Reflexivity: A Concept and its meanings for Practitioners Working with Children and Families. Critical Social Work. University of Windsor.

Darawsheh, W. (2014). Reflexivity in Research: Promoting rigour, reliability and validity in qualitative research. International Journal of Therapy and Rehabilitation., 21(12).

Darrow, A. A. interviewed by G. T. (2013). Music therapy and special music education: Interdisciplinary dialogues. Approaches: Music Therapy \& Special Music Education, 5(1), 12-17.

Davidson, G. (2012). Community Music Therapy A Pathway to a Sense of Belonging in a School Environment. Massey University and Victoria University of Wellington. Retrieved from http://researcharchive.vuw.ac.nz/bitstream/handle/10063/3002/thesis.pdf?sequenc $\mathrm{e}=2$

Edwards, J. (1999). Considering the Paradigmatic Frame: Social science research approaches relevant to research in music therapy. The Arts in Pyschotherapy, 26(2), 73-80.

Gaham, J. (2004). Communicating with the uncommunicative: music therapy with preverbal adults. British Journal of Learning Disabilities, (32), 24-29. 
Geist, K., McCarthy, J., Rodgers-Smith, A., \& Porter, J. (. (2008). Integrating music therapy services and speech-language services for children with severe communication impairments: a co-treatment model. Journal of Instructional Psychology, 35(4), 311-316.

Geretsegger, M., Elefant, C. Mössler, KA., Gold, C. (2014). Music therapy for people with autism spectrum disorder. Cochrane Database of Systematic Reviews, (6). http://doi.org/10.1002/14651858.CD004381.pub3.

Gosine, J., Hawksley, D., \& Quinn, S. L. (2017). Community Building Through Inclusive Music-Making. Voices: A World Forum for Music Therapy, 17(1). http://doi.org/10.15845/voices.v17i1.893

How, S. L. (2014). Interaction within the Therapeutic Relationship: Exploring the Relationship between the Music Therapy Practices of a Music Therapy Student and the Concepts Used in Intensive Interaction. Victoria University of Wellington. Retrieved from http://researcharchive.vuw.ac.nz/handle/10063/3729

Jörg, F. (2017). From Assistance to Co-Therapy. In E. Strange, J; Odell-Miller, H; \& Richards (Ed.), Collaboration and Assistance in Music Therapy Practice: Roles, Relationships, Challenges. (1st ed., pp. 157-168). London; Philadelphia: Jessica Kingsley Publishers.

Jung, S., \& Sainato, D. M. (2013). Teaching play skills to young children with autism. Journal of Intellectual and Developmental Disability, 38(1), 74-90. http://doi.org/10.3109/13668250.2012.732220

Kern, P., \& Aldridge, D. (2006). Using Embedded Music Therapy Interventions to Support Outdoor Play of Young Children with Autism in an Inclusive Community-Based Child Care Program. Journal of Music Therapy, 43(4), 270294. http://doi.org/10.1093/jmt/43.4.270 
Laahs, J. and Derrington, P. (2016). 'Learning together: An investigation into the potential of inter-professional education within music therapy', in Approaches, 8 (1), pp. 26-41.

Lewis-Beck, M. S., Bryman, A. \& Futing Liao, T. (2004). The SAGE encyclopedia of social science research methods: In SAGE Publications Ltd. http://doi.org/doi: $10.4135 / 9781412950589$

Loewy, J., \& Loewy, J. (2004). Integrating Music, Language and the Voice in Music Therapy. Voices: A World Forum for Music Therapy, 4(1). http://doi.org/10.15845/voices.v4i1.140

Macdonald, J. (2016). Collaborative Music Therapy; Determining the Benefits and Challenges of Collaborative Work from a Student's Perspective. New Zealand School of Music, \& Victoria University of Wellington, degree granting institution.

Macintyre, C. (2016). Strategies to Support Children with Autism and Other Complex Needs. Resources for teachers, support staff and parents. Abingdon, Oxfordshire, UK.: Routledge.

Mathison, S. (2005). (a) Secondary analysis. In Encyclopedia of evaluation (pp. 388388). Thousand Oaks, CA: SAGE Publications Ltd. http://doi.org/doi: $10.4135 / 9781412950558 . n 502$

Mathison, S. (2005). Constructivism. In Encyclopedia of evaluation. Thousand Oaks, CA: SAGE Publications Ltd. http://doi.org/10.4135/9781412950558

McFerran, K. (2010). Adolescents, Music and Music Therapy: Methods and Techniques for Clinicians, Educators and Students. London, UK.: Jessica Kingsley Publishers.

McFerran, K. S., Thompson, G., \& Bolger, L. (2016). The impact of fostering relationships through music within a special school classroom for students with 
autism spectrum disorder: an action research study. Educational Action Research, 24(2), 241-259. http://doi.org/10.1080/09650792.2015.1058171

Mills, A. J., Durepos, G. \& Wiebe, E. (2010). Methods: Thematic Analysis. In Encyclopedia of case study research. Thousand Oaks, CA: SAGE Publications Ltd. http://doi.org/10.4135/9781412957397

Mossler, K., \& Schmid, W. (2016). What's this adorable noise? Relational qualities in music therapy with children with autism. Nordic Journal of Music Therapy, 25(sup1), 51-51. http://doi.org/10.1080/08098131.2016.1179960

Munro, H. (2017). Music Therapists' Experiences of Working with Staff in Sessions. In E. Strange, J; Odell-Miller, H; \& Richards (Ed.), Collaboration and Assistance in Music Therapy Practice: Roles, Relationships, Challenges. (pp. 31-45). London; Philadelphia: Jessica Kingsley Publishers.

Nordoff, P., \& Robbins, C. (1977). Creative Music Therapy: Individualized Treatment for the Handicapped Child. New York, NY: John Day Co.

Oldfield, A. (2006). Interactive music therapy - a positive approach: Music therapy at a child development centre. London: Jessica Kingsley Publishers.

Pellitteri, J. (2000). Music therapy in the special education setting. Journal of Educational \& Psychological Consultation, 11(3-4), 379-391. http://doi.org/http://dx.doi.org/10.1207/S1532768XJEPC113\&4_06

Perry, L. (1993). What's Up? In Four Non Blondes - "Bigger, Better, Faster, More" (Recorded 13th October 1992). Interscope Records.

Raglioa, A., Traficanteb, D., Oasi, O. (2009). Autism and music therapy. Intersubjective approach and music therapy assessment. Nordic Journal of Music Therapy, 20(2), 123-141.

http://doi.org/http://dx.doi.org.helicon.vuw.ac.nz/10.1080/08098130903377399 
Register, D. (2002). Collaboration and consultation: A survey of board certified music therapists. Journal of Music Therapy, 39(4), 305321.

Richards, L. (2009). Handling Qualitative Data: Practical guide. (2nd ed.). London: SAGE Publications Ltd.

Rickson, D., \& M. (2014). Creating music cultures in the schools: a perspective from community music therapy. Gilsum NH: Barcelona Publishers.

Rickson, D., \& Twyford, K. (2011). Music therapy consultation in a New Zealand school: Staff members' perceptions of outcomes. The New Zealand Journal of Music Therapy, 9, 61-85. The New Zealand Journal of Music Therapy, 9, 61-85.

Ritter-Cantesanu, G. (2014). Music therapy and the IEP process. Music Therapy Perspectives, 32(2), 142-152. http://doi.org/10.1093/mtp/miu018

Ropp, C. R. (2006). Special Education Administrators' Perceptions of Music Therapy in Special Education Programs. Music Therapy Perspectives, 24(2), 87-93. http://doi.org/10.1093/mtp/24.2.87

Stevenson, K. (2003). Music therapy assisted communication with children with severe disabilities. The New Zealand Journal of Music Therapy, 1(82-92).

Stige, B. (2002). Culture-centred music therapy. Gilsum, NH: Barcelona Publishers.No Title. NH: Publishers., Barcelona.

Stige, B. \& Aaro, L. E. (2012). Invitation to community music therapy. New York: Routledge.

Strange, J. (2017). Assistants as Interaction Partners. In E. Strange, J; Odell-Miller, H; \& Richards (Ed.), Collaboration and Assistance in Music Therapy Practice: Roles, Relationships, Challenges. (1st ed., pp. 18-30). London; Philadelphia: Jessica Kingsley Publishers. 
Talmage, A., Watson, J. Willis, M. (2014). Navigating cross-cultural pathways on Rarotonga: An exploratory collaboration bringing together a music therapist a speech- language therapist, the Cook Islands Ministry of Education and a day centre for adults with intellectual and physical disabilities. The New Zealand Journal of Music Therapy, 12, 58-86.

Thompson, A., \& McFerran, S. (2015). Music therapy with young people who have profound intellectual and developmental disability: Four case studies exploring communication and engagement within musical interactions. Journal of Intellectual and Developmental Disability, 40(1), 1-11. http://doi.org/https://doi.org/10.3109/13668250.2014.965668

Twyford, K. \& Watson, T. (2008). Integrated team working: Music therapy as part of transdisciplinary and collaborative approaches. London; Philadelphia: Jessica Kingsley Publishers.

Twyford, K., \& Watters, S. (2016). In the Groove: An Evaluation to Explore a Joint Music Therapy and Occupational Therapy Intervention for Children with Acquired Brain Injury. Voices: A World Forum for Music Therapy, 16(1). http://doi.org/10.15845/voices.v16i1.851

Warnock, T. (2012). Vocal Connections: How Voicework in Music Therapy Helped a Young Girl with Severe Learning Disabilities and Autism to Engage in her Learning. Approaches : Music Therapy \& Special Music Education, 4(2), 85-92.

Watson, T. (2017). Supporting the Unplanned Journey. In Collaboration and Assistance in Music Therapy Practice: Roles, Relationships, Challenges. (pp. 141-156). London; Philadelphia: Jessica Kingsley Publishers.

White, B. (2011). “What Sound Can You Make ?" A Case Study of a Music Therapy Group for Children with Autism, Learning Disabilities and Challenging Behaviours. Approaches: An Interdisciplinary Journal of Music Therapy., 7(2), 197-206. 
Wigram, T., Pedersen, I. and Bonde, L. (2002). A Comprehensive Guide to Music Therapy. London: Jessica Kingsley Publishers.

Wigram, T. (2004). Improvisation: Methods and Techniques for Music Therapy Clinicians, Educators and Students. London, UK.: Jessica Kingsley Publishers.

The Ministry of Education, New Zealand. (2011). Collaboration for Success:

Individual Education Plans. Wellington. Retrieved from www.learningmedia.co.nz

Code of Ethics for the Practice of Music Therapy in New Zealand, Music Therapy New Zealand (2012). 


\section{Appendices}

\section{Appendix 1:}

Raw Data from Reflective Clinical Journal Notes:

The following is an excerpt taken from my clinical journal notes. From these notes, I was able to compile my raw data used for the research. For the purpose of confidentiality, I have removed names of individuals and classrooms.

\subsection{6 .17}

- I sang a song for the teaching staff in room $\mathbf{X}$. They were eagerly waiting for the song this week. Taking turns to take the students to the toilet before morning tea time. It is nice to see them relaxed and this transfers to the students who can see them smiling and can respectively engage in the music.

- Room $\square$ : During the session today, I wanted teachers to participate in group sessions without intervening, but only when necessary. It can sometimes get a little frustrating from my point of view as a practitioner. Participating in the group sessions alongside the students is great motivation and modelling for them to see. It's okay for students to sit there and participate through listening and watching. I need to work on how to communicate this.

- Today I was asked to come and be alongside the students whilst they conduct their individual learning times. During this I worked with a young girl who was placed in a hoist/sling, where she was being encouraged to use her body to move about the room. I used the voice and guitar to motivate this young girl to walk in directions towards the music. The guitar and voice were played and sung in a rhythm that could match her gait, crescendos and anticipation was created in order to invoke motivation in his movements. Another moment I sang to a young girl who was experiencing sensory time with the teacher aide. I matched the mood and textures of the material to the sounds by changing dynamics, vocal colours and breathing techniques.... 


\section{Appendix 2:}

Initial Coding:

From my notes, I extracted all parts that were the result of collaborative musical interactions. All moments where musical situations took place alongside teaching staff and specialists were extracted for the function of interpreting and understanding what each was attempting to convey. The following is an example of some extracted information and the initial coding I gave them. Most extracts had more than one code.

\begin{tabular}{|c|c|c|c|}
\hline Reference: & Data: & Initial Code \#1: & Possible other Code \#2: \\
\hline 13.06. & $\begin{array}{l}\ldots . \text { with everyone singing. } \\
\text { The teacher who had a } \\
\text { great voice helped hold } \\
\text { this as well. }\end{array}$ & $\begin{array}{l}\text { supporting teaching staff } \\
\text { to be musical }\end{array}$ & \\
\hline 13.06. & $\begin{array}{l}\text { Encouraging teachers to } \\
\text { practice the song lyrics } \\
\text { with the students in class } \\
\text { when I am not there. I } \\
\text { recorded the } \\
\text { instrumentation and } \\
\text { hummed the melody in a } \\
\text { video recording for the } \\
\text { teachers to have a } \\
\text { resource to go by. }\end{array}$ & $\begin{array}{l}\text { Resourcing the teaching } \\
\text { staff with musical } \\
\text { materials }\end{array}$ & $\begin{array}{l}\text { Supporting teaching staff } \\
\text { to be musical }\end{array}$ \\
\hline 13.06. & $\begin{array}{l}\text { Music to compliment the } \\
\text { task of putting on a } \\
\text { jumper and gloves on a } \\
\text { student. this student had } \\
\text { very stiff spasms ... } \\
\text { difficult for him to relax } \\
\text { so that he could be } \\
\text { dressed. I used music as a } \\
\text { calming distraction, in } \\
\text { order to relax the student. }\end{array}$ & $\begin{array}{l}\text { supporting moments in } \\
\text { the daily routine. }\end{array}$ & $\begin{array}{l}\text { Musical improvisations } \\
\text { to connect teaching staff } \\
\text { and students }\end{array}$ \\
\hline 13.06. & $\begin{array}{l}\text { I sang a song for the } \\
\text { teaching staff in room } \\
\text { They were eagerly waiting } \\
\text { for the song this week. It } \\
\text { is nice to see them relaxed } \\
\text { and this transfers to the } \\
\text { students... }\end{array}$ & $\begin{array}{l}\text { singing songs to } \\
\text { encourage interaction }\end{array}$ & $\begin{array}{l}\text { supporting moments } \\
\text { with staff by singing } \\
\text { songs. }\end{array}$ \\
\hline
\end{tabular}




\section{Appendix 3:}

Compiled Coding:

My next step of the analysis was the bringing together of codes. Codes that were linked in meaning were grouped together. Similar codes along with their context in the data were evaluated and compared to interpret whether they were communicating the same idea. This process was used to compile the codes into themes.

\begin{tabular}{|c|c|c|c|c|}
\hline Reference: & Data: & Initial Code \#1: & $\begin{array}{l}\text { Possible Other } \\
\text { Code \#2: }\end{array}$ & Theme: \\
\hline 13.06. & $\begin{array}{l}\text { Another moment I sang to a } \\
\text { young girl who was } \\
\text { experiencing sensory time with } \\
\text { the teacher aide. I matched the } \\
\text { mood and textures of the } \\
\text { material to the sounds by } \\
\text { changing dynamics, vocal } \\
\text { colours and breathing } \\
\text { techniques. }\end{array}$ & & $\begin{array}{l}\text { Musical } \\
\text { improvisations to } \\
\text { connect teaching } \\
\text { staff and students } \\
\text { through learning } \\
\text { agenda }\end{array}$ & $\begin{array}{l}\text { music supporting } \\
\text { student goals }\end{array}$ \\
\hline 16.05 . & $\begin{array}{l}\text { Incorporating the individual } \\
\text { learning plan time with his } \\
\text { teacher aide to join with music } \\
\text { therapy time. A way to merged } \\
\text { both tasks and make it as } \\
\text { meaningful and functional. }\end{array}$ & $\begin{array}{l}\text { supporting } \\
\text { student goals } \\
\text { with musical } \\
\text { improvisations. }\end{array}$ & $\begin{array}{l}\text { supporting the } \\
\text { learning agenda. }\end{array}$ & $\begin{array}{l}\text { Music supporting } \\
\text { student goals }\end{array}$ \\
\hline 16.05 . & $\begin{array}{l}\text { Collaborating ideas about } \\
\text { positive play and social } \\
\text { interaction skills in a } \\
\text { classroom. The SLT was } \\
\text { happy to have me involved and } \\
\text { is interested in using } \\
\text { interactive music therapy } \\
\text { techniques to support the } \\
\text { collaboration. }\end{array}$ & $\begin{array}{l}\text { music } \\
\text { supporting play } \\
\text { skills }\end{array}$ & $\begin{array}{l}\text { assisting } \text { SLT } \\
\text { and teaching } \\
\text { staff in musical } \\
\text { ideas }\end{array}$ & $\begin{array}{l}\text { music supporting } \\
\text { student goals }\end{array}$ \\
\hline
\end{tabular}


Appendix 4:

\title{
Information Sheets and Consent Forms:
}

Example of Information Sheet for Facility:

E KŌKİ NEW ZEALAND SCHOOL OF MUSIC

VICTORIA UNIVERSITY OF WELLINGTON, PO Box 600, Wellington 6140, New Zealand

Phone +64-4-463-5369 Email music@nzsm.ac.nz Web www.nzsm.ac.nz

To whom it may concern,

I am writing to you formally to ask consent for my Master of Music Therapy research to be conducted at Allenvale School.

As you are aware, I am conducting the research for my thesis which reflects my practice as a student music therapist at your school, where I have been on placement since February 2017. This research will go towards the requirements needed in fulfilment of a Master Degree of Music Therapy at Victoria University of Wellington/ Te Kōki New Zealand School of Music. I understand that I have received preliminary consent in my appointment as a student music therapist at Allenvale School. I have also discussed the content, style, participants and ethics of my research and have gained verbal consent during a one-on-one meeting with the principal. My research proposal has been approved by the NSZM Postgraduate Research Committee in April 2017. The research is supervised by Sarah Hoskyns (A/Professor NZSM)

Email: sarah.hoskyns@vuw.ac.nz.

\begin{abstract}
:
This proposed research aims to investigate how a student music therapist used musical interactions to collaborate with teaching staff and Specialist Services in a special education setting. Music therapy in special education is commonly seen as a beneficial therapeutic intervention for children with complex needs. Music therapists in this context usually become great collaborators as they assist and support other therapy professionals and staff. This research project will examine a music therapy students' work in a new professional environment and cultural context as he conducts interactive music therapy techniques to support specific collaborations with teachers and therapy staff. The student music therapist's clinical data will be analysed using secondary analysis as the methodology and data will be coded, sorted into meaning units, and themes will then be drawn out using thematic analysis.
\end{abstract}


E KŌKĪ NEW ZEALAND SCHOOL OF MUSIC

VICTORIA UNIVERSITY OF WELLINGTON, PO Box 600, Wellington 6140, New Zealand

Phone +64-4-463-5369 Email music@nzsm.ac.nz Web www.nzsm.ac.nz

\section{Ethics:}

I, the researcher and music therapy student will provide the clinical data for this research project. Due to the secondary analysis of personal material that is self-reflective, no direct participants are being studied. I will abide by the Code of Ethics for the Practice of Music Therapy in New Zealand and Victoria University of Wellington Human Ethics Policy and Guidelines. Ethical approval for this type of study has already been gained through the music therapy programme leaders at the New Zealand School of Music. Careful consideration has been taken into account of the Treaty of Waitangi and the affects that this research may have on New Zealand Māori.

Informed consent will be obtained by parents/guardians of the participants who may be indirectly involved in formative vignettes for the research project. Even though this research is focussing on self-reflective clinical notes and written material, it is important that action is taken for the protection of those indirectly involved in the research process. No real names of participants will be used in any of the research as a means of protecting staff and students' identities.

The school can choose to have its name made anonymous or to be included within the research. I must state that even if the school wishes to remain anonymous, it does not give means of full anonymity. This is due to the fact that New Zealand Special Education schools are few and there is a chance that information given could be connected to the school.

By formally consenting this research, you are giving me the right to use my clinical notes and materials as data for my research. This data will be held in a locked filing cabinet under the care of my supervisor for a period of five years, after which it will be destroyed. My research will be published by the library of Victoria University of Wellington, and I may offer the results to music therapy or other journals.

Please find an attached copy of the approved research proposal and a copy of the ethics approval letter from the Human Ethics Committee of Victoria University of Wellington. Feel free to acknowledge any concerns you may have and to contact my supervisor (email address above) if you need to ask further questions.

May I please have a written response to the consent of this research by the $24^{\text {th }}$ May, 2017. An email reply will be fine.

Thank you, Kind Regards,

Devin Brooks 
Example of Vignette Consent Form:

T E KŌKĪ NEW ZEALAND SCHOOL OF MUSIC

VICTORIA UNIVERSITY OF WELLINGTON, PO Box 600, Wellington 6140, New Zealand

Phone +64-4-463-5369 Email music@nzsm.ac.nz Web www.nzsm.ac.nz

\section{The Use of Musical Interactions to Collaborate with Teaching Staff and Specialist Services at a Special Education School.}

\section{VIGNETTE PARTICIPANT CONSENT FORM}

As you have been made aware, I am required to investigate research which will reflect on my practice as a music therapy student at your school.

Written vignettes are to be included in my completed exegesis which will be submitted to Victoria University on the $1^{\text {st }}$ December 2017. My written vignettes are short descriptive narratives/stories that portray and highlight key moments in the life of my work as a music therapy student. These vignettes can help support my findings by illustrating ideas within the context of my work.

I would like to write two short vignettes that showcase some of the meaningful moments that we shared during music therapy in your classroom. Your name and names of students and teaching staff will not be used in the vignettes. Though, please understand that the community of the school is small and it may be possible that you or students could be identified through the vignette.

For any further information please feel free to contact my Research Supervisor Dr Sarah Hoskyns using the contact information above.

I have read the Information above and have had the details of the study explained to me. My questions have been answered to my satisfaction, and I understand that I may ask further questions at any time.

I agree/do not agree to clinical journal notes involving observations made from music therapy in my classroom being used for reflection and analysis for research purposes.

I understand I can withdraw my information from the research up till the end of the data analysis $\left(30^{\text {th }}\right.$ November 2017)

I agree to my data being used in this study under the conditions set out in the information given above.

\section{Signature:}

\section{Full Name - printed}

\section{Date:}


